\title{
The Cold War is Over: What Now?
}

S.S. Hecker

The following article is based on the plenary lecture presented at the 1994 MRS Meeting on November 28, 1994 in Boston. S.S. Hecker is director of the Los Alamos National Laboratory.

In the spirit of trying to keep an audience interested at this time of the evening, I decided to start my presentation with the question and answer session. And since you have not yet had the opportunity to question my hypotheses, I have provided my own questions.

\section{Why focus on the end of the Cold War for an MRS audience?}

As you might imagine, the end of the Cold War has elicited an intense reexamination of the roles and missions of institutions such as the Los Alamos National Laboratory. That fact was brought home to me rather dramatically last year when at the 50th anniversary celebration of the founding of the laboratory at Los Alamos, the scientific director of one of the two Russian nuclear weapons laboratories presented me with a piece of a dismantled Russian nuclear warhead with the inscription, "From Russia with love."

During the past few years, the entire defense establishment has undergone substantial consolidation, with a concomitant decrease in support for research and development, including in areas such as materials. The defense industry is downsizing at a rapid pace. Even universities have experienced significant funding cutbacks from the defense community.

I view this as a profound time in history, bringing changes encompassing much more than just the defense world. In fact, support for science and technology is being reexamined across the board more completely than at any other time since the end of World War II when Vannevar Bush issued his policy classic, Science: The Endless Frontier. ${ }^{1}$

\section{Are changes in the academic and industrial sectors really that profound? And do these changes reflect only the end of the Cold War?}

Yes, they are that profound! No, they reflect much more than just the end of the Cold War. We have a confluence of sever- al driving forces in addition to global geopolitical security changes. Over the past decade we have witnessed the emergence of a global marketplace and, as expressed by Peter Drucker, ${ }^{2}$ the world is in the midst of a social transformation to a knowledge-based society.

The end of the Cold War has realigned the world's balance of power and focused public attention increasingly on the vexing social problems facing the United States and the world. International competition has dramatically changed U.S. industry. To stay competitive, U.S. companies have found it imperative to adopt quality management approaches and to integrate R\&D much more closely with product design and manufacturing. This has generally led

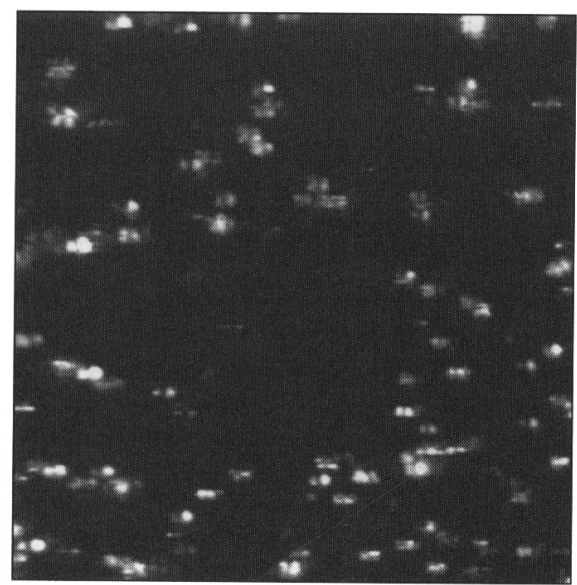

Figure 1. Locations of individual rhodamine $6 \mathrm{G}$ molecules on a silica surface imaged by near-field scanning optical microscopy. The image size is approximately $8 \mu \mathrm{m}$ by $8 \mu \mathrm{m}$. The image is formed by transmitting light through a $0.25 \mu \mathrm{m}$ aperture, scanning the aperture $\sim 10 \mathrm{~nm}$ above a silica surface, and detecting fluorescence at each position. Achieving single-molecule sensitivity on a surface allows observation of the unique orientation, photobleaching behavior, and fluorescence lifetime of individual molecules that are otherwise buried in ensemble measurements. ${ }^{6}$ to a focus on R\&D with shorter time horizons and with less concentration on basic research at industrial laboratories. At universities, the cost of research has escalated dramatically. Many universities claim to lose money on every dollar of research received from the federal government. Industry has not come to the rescue.

\section{Does this reflect a lack of opportuni- ties? Have we run out of ideas? Or does it reflect a lack of problems for science to solve?}

I think neither! The opportunities for advances in science and technology remain great. This is especially true for materials $R \& D$, as witnessed by the 4,000 or so presentations at this [1994 MRS Fall] Meeting

The 1989 Materials Science and Encineering $^{3}$ report stated that we are entering an unprecedented time of intellectual challenge and productivity in materials science and engineering. I believe that this is even more true today than it was five years ago. The areas of exciting materials research are countless. However, I find three particularly exciting at this time.

The first is in atomic resolution and nanoscale structures and devices. Atomic resolution characterization with transmission electron microscopy (TEM) and scanning tunneling microscopy (STM) has become routine. Researchers are now also using atomic force microscopy (AFM) reasonably routinely. Subsurface imaging has been opened up by the development of the magnetic resonance force microscope which combines the three-dimensional imaging of magnetic resonance imaging (MRI) with the sensitivity and resolution of AFM. ${ }^{4}$ Researchers expect to achieve 1 to $10 \mathrm{~nm}$ resolution at depths of 200-300 $\mathrm{nm}$ below the surface in a few years. Remarkable observations of surfaces, including single-molecule detection, are made with the recently developed near-surface optical microscope. (See Figure 1.) Nanoscale microstructures-including nanoelectronic quantum devices as well as composite ceramic structures of $\mathrm{MoSi}_{2}$ and $\mathrm{SiC}$ that have remarkable elastic properties ${ }^{5}$-are synthesized by numerous techniques.

The second area is modeling, simulation, and large-scale computing in materials science. The enormous progress in high-performance computing (more than a factor of $10^{12}$ over the past 50 years) has opened up new vistas for materials research. Recent advances in massively parallel computing are especially exciting because many materials problems lend themselves naturally to the massively parallel processor approach. (See Figure 


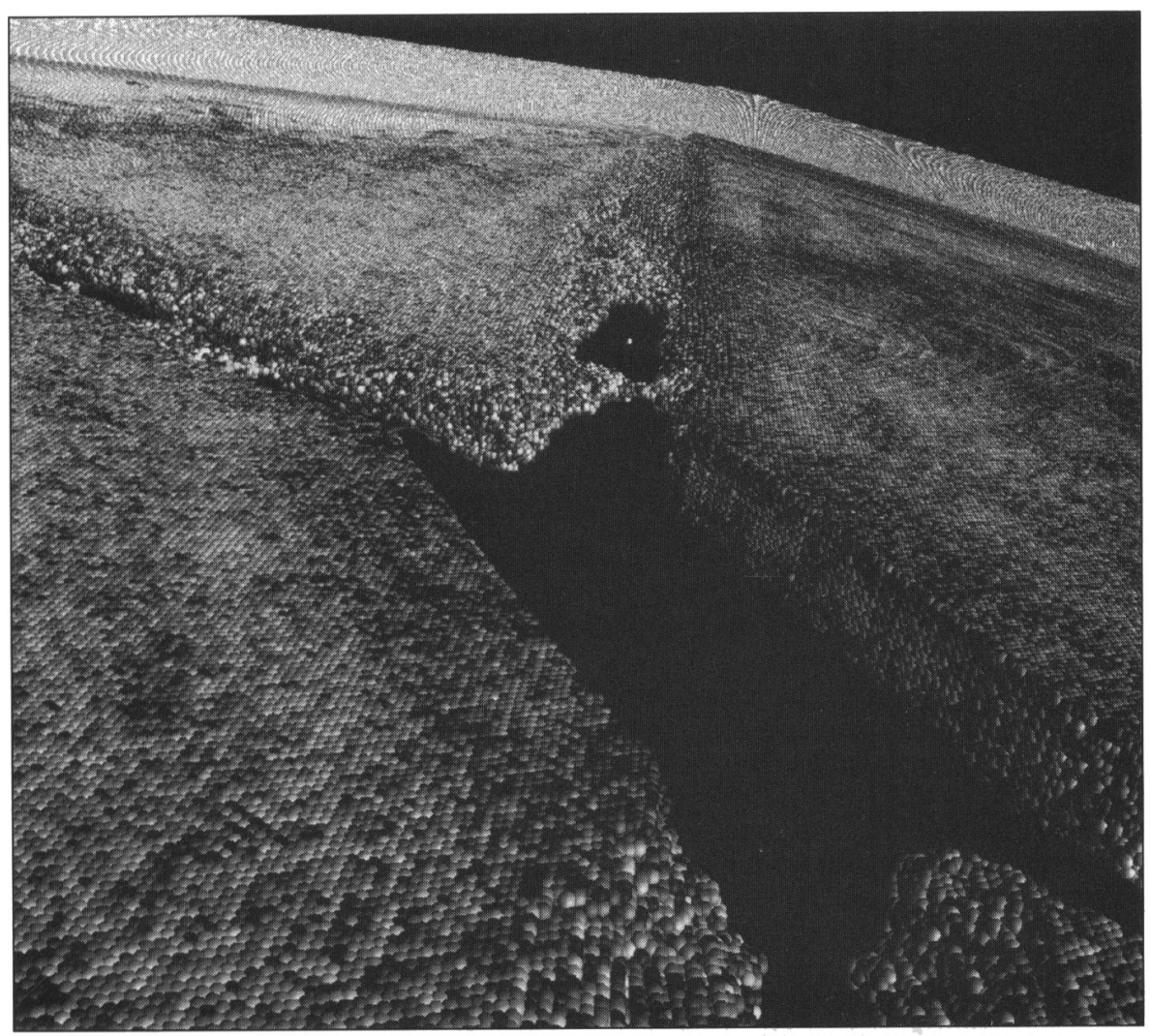

Figure 2. Snapshot from a 38 million atom molecular dynamics simulation of fracture performed on the 1024 processor CM-5 at Los Alamos National Laboratory. A thin plate has been prestrained and has fractured due to an initial defect. ${ }^{7}$

2.) Researchers are beginning to span the length scale for materials; that is, current atomistic calculations can handle problems simulating hundreds of millions of atoms. The size of such simulations is approaching micron-size features, which are now fabricated for electronic devices. (See Figure 3.) At the same time, adaptive learning simulations (using neural nets, for example) are beginning to be used successfully for process control in complex material synthesis and processing applications.

The third area is biomolecular systems. I believe that biosciences will not only be one of the intellectually most challenging scientific frontiers in the next century, but will also lead to many practical innovations, including in the materials field. This will range from biomimetic materials to using biomolecules in the processing and characterization of materials. For example, bioscientists at Los Alamos and collaborators from other institutions have recently used synchrotron $x$-ray studies at low temperatures to unravel how proteins function in myoglobin (what some call the hydrogen atom of the biosciences). (See Figure 4.) Proteins share many characteristics of glasses, such as regions of conformational disorder on the atomic scale, a glass transition temperature (near $180 \mathrm{~K}$ ), and a highly degenerate ground state. Yet an ensemble of proteins can form a crystal and such crystals of glasses can diffract to atomic resolution. Protein structures appear random on a space-filling model, but in fact they are highly organized when considered from the energy flow point of view. Chemical, electrical, or light energy deposited at one place in a protein is typically put to functional use with high efficiency, often at a point far removed from where it was deposited. Such advances allow one to dream of protein engineering, that is, using the remarkable range of protein functions to create advanced biomaterials tailored at the atomic level for specific properties.

Applied R\&D also provide great opportunities. The infrastructure in the United States is in dire need of repair and modernization. Transportation and waste management are chronic concerns and the information infrastructure represents a new opportunity for competitive advantage. The environment will require increased attention so that we can sustain economic growth (in the United States and around the globe) without sacrificing our quality of life. Also, many societal problems have some components in which science can help.

We have thus not run out of problems to solve where science can make a difference. Continued progress in science will indeed be imperative for industrial competitiveness. I believe that over the next decade most industrialized nations will be able to apply quality principles to extract every last bit of productivity out of a nation's industries (such as through quality management, reduced cycle times, and integrated $R \& D$ functions). The future competitive advantage of nations lies in which nation is able to continue to discover new and novel processes and product ideas. Scientific discovery will be key to international leadership.

\section{So, we have lots of ideas, we have lots of problems, we need less defense-so why not simply apply the peace dividend to this new class of problems? Shouldn't this actually help materials research?}

The peace dividend is peace! The Clinton administration's strategy was to redirect defense $R \& D$ to civilian $R \& D$, to balance the federal $R \& D$ budget from $60 \%$ defense $/ 40 \%$ civilian to $50 / 50$. However, the savings from defense have 


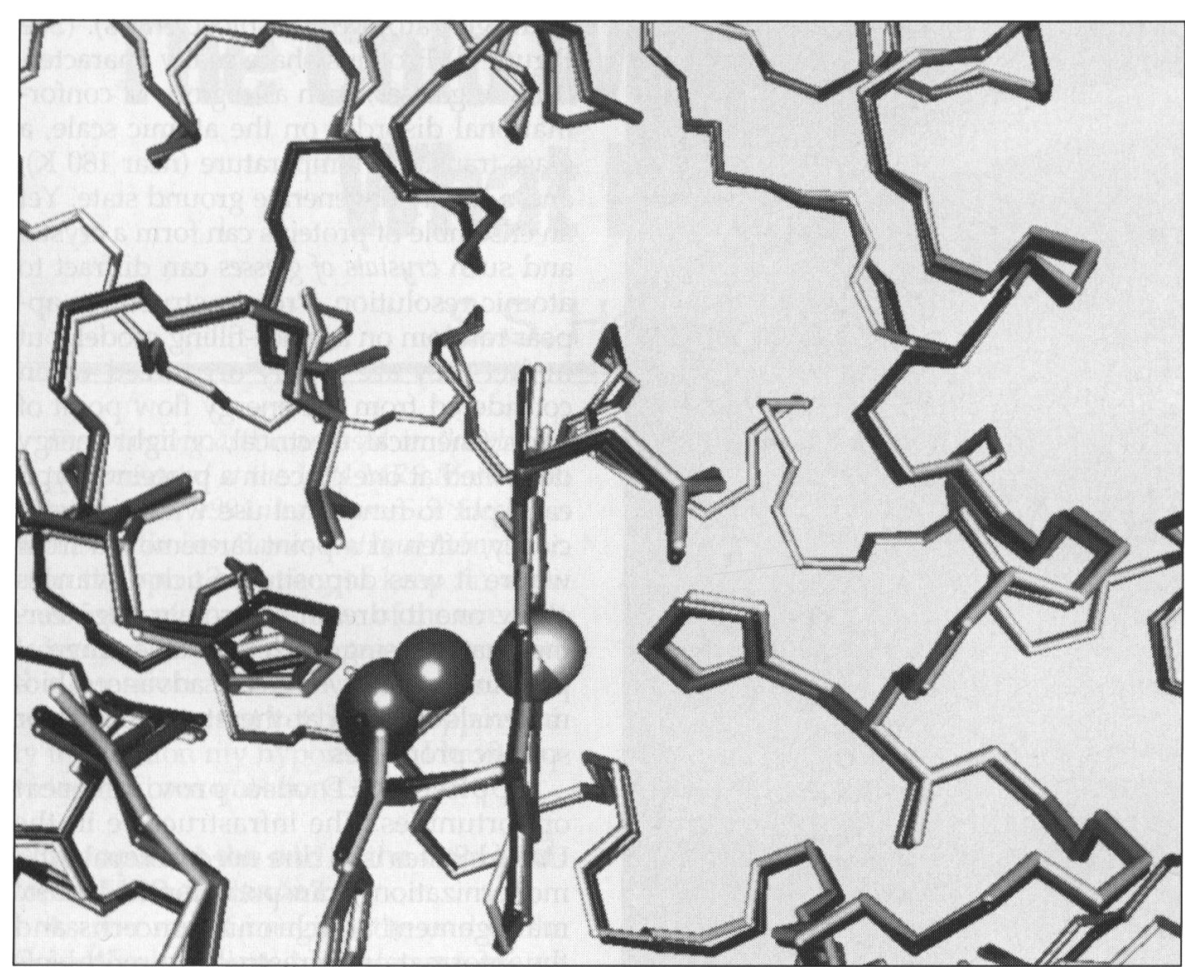

Figure 4. Three frames of a movie showing the protein myoglobin at work. The cartoon shows superimposed partial structures of myoglobin in three states: with carbon monoxide bound (gray), in an intermediate state with carbon monoxide free inside a binding pocket (black), and without any ligand (white). The view is along the plane of the heme (center); the cylinders show bonds between backbone atoms and atoms of selected residues, while the heme iron and $\mathrm{CO}$ atoms are rendered as spheres. The structures were obtained by $x$-ray diffraction at cryogenic temperatures. ${ }^{8}$

been slow in coming, even with the dramatic cutbacks in the defense industries. After 50 years of hot and cold wars, many people were in line for federal support, including debt service for past spending to win those wars.

However, the biggest obstacle to continued strong federal support for science and technology funding is a lack of national consensus of the government's role in supporting science and technology for civilian purposes. We are just beginning to understand how profoundly the Cold War has shaped modern government. In a recent Foreign Policy article, Deudney and Ikenberry ${ }^{9}$ discuss how the Cold War not only influenced the defense budget, but also how it forged a new social bargain. The Cold War provided the impetus for meeting many progressive social goals without having to establish a consensus for a domestic agenda. (Two important examples are the National Defense Education Act and the National Defense Highway Act of the 1950s). The Cold War strengthened U.S. leaders' ability to mobilize public support for national goals. In fact, Deudney and Ikenberry claim that the demands of war (both hot and cold) enhanced the power and prestige of the federal government (especially the presidency) much beyond what existed before World War II, and, in fact, much beyond what the framers of the constitution had in mind.

The end of the Cold War has eroded national political cohesiveness, especially in support for science and technology. Very few areas of science and technology will be immune. This appears to be the mood of the new Congress. Civilian or societal problems appear to be much less compelling for a strong federal role. In fact, Deudney and Ikenberry ${ }^{9}$ claim that institutions oriented toward domestic needs leave little room for creative or bold use of executive power. The Cold War has apparently shaped the presidency to leave it ill-designed for pursuing a domestic agenda (such as health care, homelessness, environment, drugs, and crime).

So, in retrospect, defense was easy! Providing for defense is a role reserved for the federal government. Defense exer- cised all parts of the science and technology spectrum from research to manufacturing. In the years following the war, defense helped to spawn entire new industries such as electronics and computers. The threat to U.S. national security during World War II and the Cold War provided sufficient justification to support a robust science and technology program. Areas such as materials science and engineering, which represent a vital tie between science and applications, heavily supported during the past 50 years, now suffer from cutbacks experienced over the past few years. The loss of consensus will be difficult to replace.

The challenge now is to build a new, compelling basis of support for an active government and the continued federal investment in science and technology without the help of an external threat.

\section{Why can't we substitute economic war for military war? Could economic com- petitiveness not become the external threat and thereby constitute the prin- cipal organizing theme for federal research support?}

I agree with Cohen and Noll ${ }^{10}$ who recently articulated the reasons why economic competitiveness cannot replace defense as the principal theme for federal research support. To justify federal support for industry one must be able to demonstrate that the benefits accrue principally to the public. Yet, to make an impact, the benefits must also accrue to specific firms in an industry. Cohen and Noll point out that the often-cited Ministry of International Trade and Industry success in Japanese government support of Japanese industry has principally benefited industrial cartels, not necessarily the Japanese public.

Yet, much of the scientific challenge of the future will unquestionably arise from commercial applications. We have already seen advances in commercial microelectronics outstrip advances in military electronics. Much of the nanoscale materials work will be driven by the information and electronics industries. The focus in industry has moved to increased productivity and integrated $R \& D$ to reduce product cycle times. The scientific community must be closely allied with industrial firms to translate scientific discovery into applications and to provide the intellectual stimulus for further scientific discovery. This synergy of science and applications, for example, made AT\&T Bell Laboratories one of the foremost scientific laboratories of this century.

Ensuring the availability of future scientific discoveries in industry remains an 
unanswered challenge today. Clearly, a tighter integration of industry with universities will play a key role. I believe that the best of the national laboratories in the United States will also be able to aid this process in areas of science and technology that they require for their government missions. These naturally include such areas as high-performance computing, materials, sensors, and lasers. Very few question the government's role in supporting basic research. However, I believe that supporting high-risk, long-term applied research in areas that are key to future industrial competitiveness will also be imperative. The exact mechanisms will be debated for some time to come. At this time, I believe we should continue some of the experiments that the federal government has launched over the past five years and to assess their efficacy.

\section{Is the overall outlook really that bleak?}

No, not really. Actually, there is lots of good news. After all, we won the Cold War. We are rolling back the nuclear threat facing humankind. Communism is defeated and shown to be a bankrupt political system. China, Russia, and India are on their way to a market-based economic system. Gone is the idea that the United States will give up manufacturing and become a service society. U.S. companies top the world in many areas of manufacturing and U.S. productivity is highest in the world. The semiconductor industry just announced record profits and market share. Even the U.S. auto industry has learned to compete, building better cars and trucks than ever, and is making money again. U.S. universities are still the envy of the world. Finally, the national laboratories are working more effectively with industry than ever before (the DOE laboratories alone have over 1,000 cooperative R\&D agreements with U.S. firms). So, there is lots to cheer about as well.

However, federal R\&D investments in the civilian sector remain controversialdespite that the economic return on investment in $R \& D$ has been shown to be several times as high as that for other forms of investment. The burden of demonstrating public good of that investment must constantly be demonstrated. In addition, the effectiveness of the government's role must be demonstrated.

\section{Why isn't the government's role a nat- ural? If the government does not play a role here, whose job is it?}

To a large extent we are back to dealing with the end of the Cold War and the lack of a clear public consensus on the civilian role of the federal government. Federally funded $R \& D$ also provides a serious management dilemma. The government has great difficulty judging performance of R\&D contracts. It is much more difficult to define the product of R\&D than it is for other forms of government procurement. Hence, monitoring the performance of private contractors (industry, laboratories, or universities) has become a big government undertaking. The government's safeguard is to impose rigorous cost-accounting requirements and to audit mercilessly to stamp out potential waste, fraud, and abuse. And, without an easily identifiable product, the government focuses on process. Yet, of all institutions, the government is ill-equipped to determine process. The private sector, on the other hand, has found that to increase productivity we cannot take the time to focus on audits. It only slows down production.

This type of management stresses regulations and oversight instead of effectiveness, and process over product. Hence, we wind up with 15 pages of requirements for sandwich cookies in the DOD and 30,000 individual requirements to run one of our nuclear facilities in the DOE. It leads to the government's becoming risk averse-an affliction especially deadly for R\&D institutions. Without a vision-without a renewed focus on what to do-there can be no effective government leadership.

\section{OK, so what's the answer?}

There is no single, simple answer for a national consensus for federal research to support a domestic agenda. My best shot is sustainable development and industrial ecology. The government has an important role to play in assuring that economic growth leads to a sustainable future in which the nation achieves its economic, environmental, and energy goals simultaneously, without compromising the ability of future generations to meet their own needs. (See Figure 5.) The Earth is a finite system. Rapid population growth and the industrialization of the less-developed countries threaten the Earth's carrying capacity. Our own industrial ecosystems and those of less-developed countries must be developed within the constraints of the natural ecosystem.

In the United States, this will require a fundamental shift from waste management to pollution prevention, efficient use of resources, and industrial ecology defined broadly to include how energy, raw materials, technology, and environmental considerations may be integrated throughout the economy to provide for a sustainable future. ${ }^{11}$ Technology is the key to sustainability. I believe it will also deter the clash between environmentalists and industrialists over environmentally responsible human behavior.

\section{Isn't sustainable development just a political fad? Will it not die when the new Congress takes over?}

Well, I must admit that the term sustainable development carries a lot of political baggage. It appears to polarize society between those who may want to return to a Malthusian world where humans exist at bare sustenance levels and those who wish to return to the early days of the industrial revolution. Nevertheless, the general concept is right. It calls for environmentally responsible development and it provides an opportunity for the government to play a constructive, partnership role with the private sector and with our great universities, instead of relying strictly on federal regulations to ensure environmental quality.

I believe that technology for sustainability provides an appropriate organizing theme for federal support. It incorporates concerns over natural resources, energy, and environment, which are areas of public concern. It brings together government and the private sector in developing technologies for a sustainable future. These issues are so complex and interwoven that industry cannot be expected to design a solution by itself. Many of the promising technologies are sufficiently speculative that their development will pose a very high risk for industry alone. There should be a premium for maximum diffusion of technologies to other firms and industries. Furthermore, our environment is a commons, and as Garrett Hardin pointed out in his seminal essay, ${ }^{12}$ individuals, including individual firms, acting in their own self-interest, will eventually destroy that commons. Thus the benefits of much of this work accrues to the public rather than individual firms, justifying federal support for cooperative R\&D. What is required is a strong partnership between industry, universities, and the federal government, using all of the technological resources the country has to offer. It requires a long-term, patient approach for acceptable solutions. The bottom line is that technologies for sustainability represent an area where market forces have not and, in most likelihood, will not lead to the correct solution.

Technologies for sustainability also offer hope for international cooperation where the vision of a better quality of life for all people on earth through technology may actually replace a foreign military threat as the national consensus for action in the United States. 

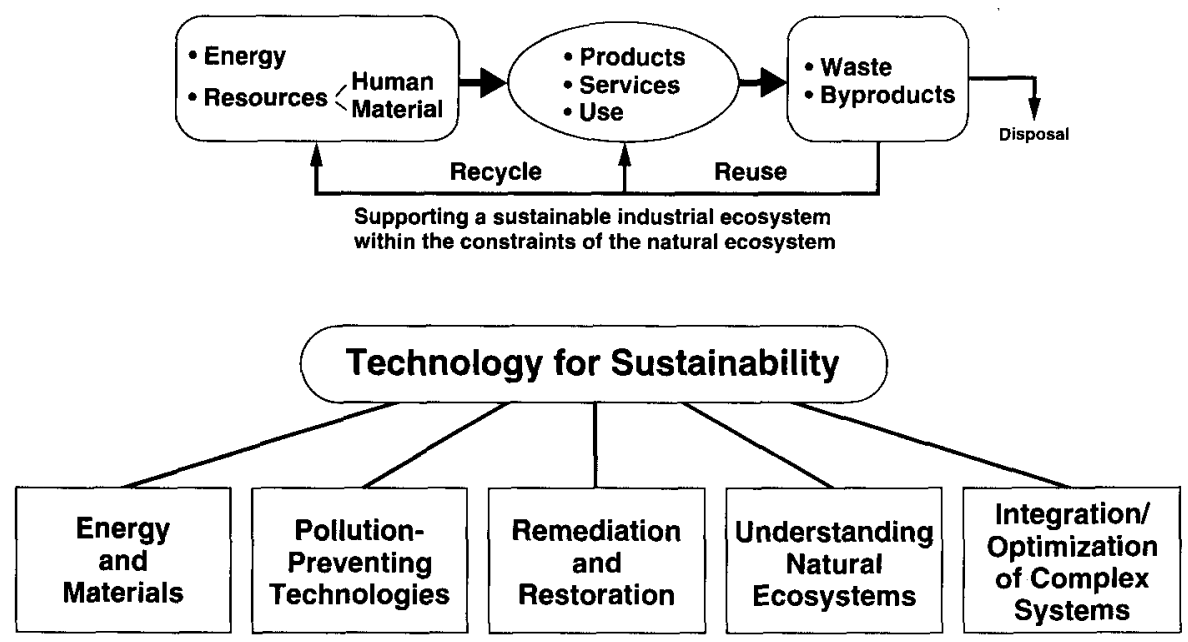

Figure 5. Technology for sustainability could become an organizing principle of the Department of Energy's existing missions in energy and environment and in the emerging mission of industrial ecology.

\section{Let's turn to the DOE laboratories. What do you believe should be the role of the laboratories?}

I believe that the role of the DOE laboratories has to be defined in the spirit of the larger question of science and technology in the United States. In fact, it should be done as part of redefining science policy. The time has come to redefine the Vannevar Bush policy of 50 years ago. If the principal role of universities is to educate (with research being a crucial component of the mission), and the principal role of industry is to provide products and services to create wealth, then the principal role of the federal laboratories is to provide science and technology for the government in partnership with these sectors.

The DOE laboratories' single most important competency is the ability to field interdisciplinary teams of scientists and engineers to conduct complex, largescale, science-intensive projects. The laboratories provide government with a mechanism to address complex, long-term problems of national importance and to redeploy them quickly to meet emerging national priorities. But, for the DOE laboratories to be effective, they must have compelling national missions and they must nurture good science. With the compelling missions in hand, I believe that the laboratories can also serve the broader national interest by working with other federal agencies and through cooperative $R \& D$ with industry in areas where the laboratories possess special expertise.

For Los Alamos, we have identified the core mission as reducing the nuclear danger, which means we would hold the stewardship of the nuclear weapons in the enduring stockpile, support the dismantling and potential remanufacturing of weapons, manage and dispose of the nuclear materials inventory, support nonproliferation and counterproliferation years of weapons production. Great science will be crucial for the conduct of this core mission. To deliver and enhance the science it will be imperative that Los Alamos function as a truly multiprogram national laboratory contributing to civilian and conventional defense missions. ${ }^{14}$

\section{What does that role bode for materials R\&D at the laboratories and how does that affect the rest of the materials community?}

Many of the problems encompassed by the missions appropriate for the DOE laboratories are complex and long term. Historically, these problems have had a strong materials component. I expect that to continue. For example, one of the greatest concerns in nuclear weapons stewardship will be the aging of weapons as we are faced with keeping current weapons in the stockpile long beyond their design lifetimes. If necessary, we

Material Matters is a forum for expressing personal points of view on issues of interest to the materials community. activities, and clean up the legacy of 50 would like the plutonium components to last somewhere between 50 and 100 years by requalifying them for service. Such requirements will place a premium on materials characterization and understanding. We expect to develop novel nondestructive evaluation techniques such as neutron radiography and resonant ultrasound. Likewise, the rest of the reducing-the-nuclear-danger mission presents significant materials challenges.

Dealing with the plutonium legacy also offers an enormous materials challenge. At Los Alamos, we are developing an accelerator-based transmutation concept that opens the possibility of transmuting nuclear wastes to less toxic forms, burning the world's excess plutonium, and producing energy from a noncritical assembly using the spallation neutrons produced by an accelerator. The materials and engineering challenges of such a system are immense.

Technologies for sustainability offer a great variety of materials challenges. Materials and energy are the currencies that flow in production processes. Materials must be recycled efficiently back into the production loop so that little or no waste is generated. Technologies such as high-temperature superconductors represent enormous potential for energy savings. Pollution-preventing technologies and products will put a premium on designing for the environment up front and materials considerations will be critically important. For the materials researcher, Brad Allenby ${ }^{15}$ points out that intelligent choice of materials is a sine qua non of environmentally preferable designs.

I expect the DOE laboratories to continue as key players in the national materials community. All of the laboratories house national user research facilities. These include light sources, neutron facilities, and sophisticated transmission electron microscopes. The user facilities serve the university and industrial communities along with the national laboratories. In recent years, the laboratories have also made available many of their synthesis and processing facilities to the materials community at large. Novel partnerships between universities and laboratories, such as the joint National High-Magnetic Field Laboratory between the Florida State University system and Los Alamos, have been developed. Future emphasis must clearly be on leveraging the federal investment in the laboratories to support not only the government, but also universities and industry. Much more can be done in some of the emerging areas of materials research using the national laboratories' capabilities in areas such as high- 
performance computing and biosciences.

To wrap up, I find no lack of ideas in the scientific community and no lack of important national or global problems for science to solve. But, in retrospect, the Cold War was easy. The defense umbrella allowed us to sweep many of our differences under the rug. Now we must develop a new consensus for a national science and technology agenda. Everyone must play a role-universities, industry, and the national laboratories. We must work more closely together than ever before. Organizations such as the Materials Research Society will play a more important role in the future to help set the national research agenda, especially since materials will retain such a vital role. The good news is that we can collectively help shape the national directions. As Peter Drucker said, "The best way to predict the future is to create it."

\section{References}

1. V. Bush, Science, The Endless Frontier: $A$ Report to the President on a Program for Postwar Scientific Research (National Science Foundation, Washington, DC, 1945).

2. P. Drucker, The Atlantic Monthly, November, (1994) p. 53.

3. Materials Science and Engineering for the 1990s: Maintaining Competitiveness in the Age of Materials (National Academy Press, Washington, DC, 1989).

4. P.C. Hammel, G.J. Moore, and M.L. Roukes, in the Workshop Summary Report: Industrial Applications of Scanned Probe Microscopy (NISTIR \#5520, 1994) p. 112.

5. H. Kung, M. Nastasi, C.M. Czarnik, T.R. Jervis, and J-P. Hivonen, Mater. Res. Soc. Symp. Proc. 322 (1994) p. 27.

6. W.P. Ambrose, P.M. Goodwin, J.C. Martin, and R.A. Keller, Phys. Rev. Lett. 72 (1994) p. 160.

7. P.S. Lomdahl, P. Tamayo, N. Gronbech
Jensen, and D.M. Beazley, Proc, of Supercomputing 93 (IEEE Computer Society Press, Los Alamitos, California, 1993) p. 520.

8. I. Schlichting, J. Berendzen, G.N. Phillips, Jr., and R.M. Sweet, Nature (London) 371 (1994) p. 808.

9. D. Deudney and G.J. Ikenberry, Foreign Policy 94 (1994) p. 21.

10. L.R. Cohen and R.G. Noll, Sci. Am., September, (1994) p. 72.

11. B. Allenby, IEEE Circuits and Devices Magazine, January, (1994) p. 24.

12. G. Hardin, Science 162 (1968) p. 1243.

13. Task Force on Alternative Futures for the DOE National Laboratories, Alternative Futures for the DOE National Laboratories (Report to the Secretary of Energy Advisory Board, February 1, 1995).

14. S.S. Hecker, Issues in Science and Technology Spring, (1994) p. 44.

15. B. Allenby, MRS Bulletin XVII, March, (1992) p. 46.

\section{NEW CVD Gases High Purity Methylsilane}

First reported as a precursor for heteroepitaxial silicon carbide on silicon, methylsilane has more recently been identified as the precursor to a plasma-deposited siliconcarbon-hydrogen polymer which can be used as a dry processable photoresist for high resolution applications. Available in limited quantities with $\geq 99.9 \%$ purity.
Other VOLTAIX Products: (Applications) Germane, Digermane (a-Si, heteroepi-Si) Diborane, Phosphine (BPSG, a-Si, epi-Si) Silane, Disilane (a-Si, epi-Si) Trimethylboron (BPSG, a-Si)

\section{Deuterated Diborane and Trimethylboron}

Precursors for plasma deposited Tokomak wall passivation and impurity gettering coatings, in the international effort to develop hot fusion energy.

\section{Deuterated Silane}

Offered to improve the performance of silane derived silica for integrated optical waveguides. O1993 VOLTAIX, INC
For more information or to place an order
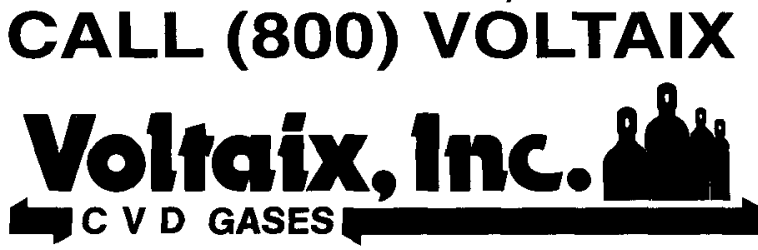

197 Meister Avenue • P.O. Box 5357 • N. Branch, NJ 08876

Fax: (908) 231-9063 - Telephone: (908) 231-9060

This is an "INFOTISEMENT" from Voltaix, Inc.

Your comments or questions are most welcome.

Circle No. 14 on Reader Service Card. 